\title{
COMBINING CRITICAL INCIDENT TECHNIQUE ANDCONTENT ANALYSIS TO INVESTIGATE CRITICAL EMOTIONAL BEHAVIORS IN SALESPERSON-CUSTOMER INTERACTIONS
}

\author{
Michel Klein ${ }^{1}$,Fanny Poujol ${ }^{2}$,Bruno Lussier ${ }^{3}$ and Christophe Fournier ${ }^{4}$ \\ ${ }^{1}$ University of Montpellier - France, michelklein@neuf.fr \\ 2 University Paris-Nanterre - France, poujol.fanny@laposte.net \\ ${ }^{3}$ HEC Montreal - Canada, bruno.lussier@hec.ca \\ ${ }^{4}$ University of Montpellier- France, christophe.fournier@umontpellier.fr
}

\begin{abstract}
In this chapter, we describe how we used both a Critical Incident Technique (CIT) survey and content analysis for collecting and identifying critical emotional behaviors in salesperson-customer interactions involving a subsequent decision to buy or not to buy. Using numbers to generate meaning from qualitative data, we present a detailed exemplar of the staged process consisting of: (1) data collection by means of an open-ended questionnaire; (2) inductive identification of categories; and (3) coding of empirical material, concerning critical emotional behaviors related to success and failure in sales interactions. Using this work, the chapter proposes a specific CIT survey process to identify critical phenomena contributing to or hindering the achievement of a specific task. This study also suggests precise category development and content analysis procedures that can be combined with a CIT survey or used to analyze written empirical material from a positivist perspective.
\end{abstract}

Keywords: Qualitative Research, Qualitative Methodology, Critical Incident Technique, CIT Survey, Critical Behaviors, Content Analysis

\section{INTRODUCTION}

The body of literature on how salespeople's emotional labor (i.e. emotion management) in interactions with customers impacts selling success is both sparse and conflicting. Researchers have found either a positive relationship between emotional labor and sales level (Brotheridge, 2006) or a negative one (Sutton \& Rafaeli, 1988). Moreover, some researchers claim that emotional authenticity has a greater impact on customers' attitudes and behaviors (Ashkanasy \& Daus, 2002; Grandey et al., 2005). Based on a critical incident technique (CIT) survey, we conducted a qualitative study with the aim to explain the impact of salespeople's emotion management on selling success in sales interactions. We combined the CIT (Flanagan, 1954) and basic content analysis (Weber, 1990) in a positivist approach (Bitner et al., 1990). The objective of this chapter is to present how to use both a Critical Incident Technique survey and basic content analysis for collecting and identifying critical emotional behaviors in salesperson-customer interactions involving a subsequent 
decision to buy or not to buy. After a presentation of the theoretical background on emotions and emotional labor, we detail the methodological process.

\section{THEORETICAL BACKGROUND OF THE EMPIRICAL STUDY}

Emotions are defined in this section. We also present the seminal conceptualization of emotion labor and its dimensions. We then expose further approaches concerning the concept of emotional labor.

\subsection{Emotions}

Emotions are mental states arising from cognitive appraisals of events or thoughts (Bagozzi et al., 1999). In addition to being a subjective experience, emotions have an expressive dimension. Indeed, they are expressed physically in gestures and postures (Bagozzi et al., 1999) and facial features or "signs" (Ekman et al., 1980). Emotions may also result in specific actions (Bagozzi et al., 1999) having an impact on one's behavior. The valence of these mental states is either "positive," pleasant, or "negative," unpleasant (Scherer, 2005).

\subsection{Emotional Labor}

In her seminal work, Hochschild (1983) defines emotional labor as "the management of feeling to create a publicly observable facial and bodily display" during face-to-face contact or, at a minimum, a verbal exchange with the customer (p. 7). Following "feeling rules," the employee is required to manage his/her emotions to produce an emotional state in another person, namely the client. Thus, emotions have an exchange value and emotional labor is part of the work role. Grandey and Gabriel (2015) add that emotional labor constitutes "an occupational category, the emotional effort or labor to perform that job, and the interpersonal expressions as the fruits of the labor" (p. 324). Emotional labor consists of three dimensions: (1) surface acting, which corresponds to a control over one's displayed emotions (Hochschild, 1983); (2) deep acting, which is control over one's felt emotions (Hochschild, 1983); and (3) the expression of spontaneous and genuine emotion, "emotional authenticity," conforming to emotional rules (Ashforth \& Humphrey, 1993). 


\subsection{Moving Beyond the Classic Emotional Labor Dimensions}

The three emotional labor dimensions can also be considered as "emotional regulation strategies" (Diefendorff \& Gosserand, 2003; Diefendorff et al., 2005). For Wharton and Erickson (1993), the purpose of the auto-regulation of emotional exhibition is to produce intended effects on others' minds. By being both self-focused and focused on others (Pugliesi, 1996), emotional labor requires control of one's own emotions and also consists in managing the customers' emotions (Thoits, 1996). Customers' emotional expressions are taken into consideration by the employee who then adjusts his or her own emotional behavior accordingly (Rafaeli \& Sutton, 1987).

However, Grandey and Gabriel (2015) suggest to "expand beyond measures of surface and deep acting" (pp. 328-329). The measures for surface and deep acting have "confounding and artifactual issues" (Grandey \& Gabriel, 2015, p. 328) that influence interpretation of findings. Indeed, surface acting may "capture" negative mood and both amplification and suppression, whereas deep acting may be confounded with motivation. Thus, other emotional labor approaches move away from the traditional surface and deep acting. One of these approaches can consist in considering both expressive regulation with other strategies to regulate one's own emotions and also the emotions of others (Grandey \& Gabriel, 2015).

\subsection{The Critical Incident Technique (CIT)}

In this section, we present the historical roots as well as the general principles of the CIT. We also indicate why the CIT combined with content analysis was chosen as a qualitative research method. We argue that the use of numbers in qualitative research makes it possible to extract more meaning from qualitative data. In addition, we specify our epistemological perspective.

\subsection{Historical Roots and General Principles of the CIT}

The Critical Incident Technique has become a widely used qualitative research method. The CIT has its origins in industrial and organizational psychology. It was "developed during World War II as an outgrowth of the Aviation Psychology Program of the US Army Air Forces (USAAF) for selecting and classifying aircrews" (Butterfield et al., 2005, p. 477). This

research method is primarily based on observation of behaviors that contributes to the success or the failure of a specific activity (Gremler, 2004). Indeed: 
The collection and tabulation of these observations make it possible to formulate the critical requirements of [this] activity. A list of critical behaviors provides a sound basis for making inferences as to requirements in terms of aptitudes, training, and other characteristics. (Flanagan 1954, p. 355)

The critical incident approach can focus not only on cognitive, conative, but also on emotional behaviors (Bitner et al., 1990, p. 73). These behaviors are considered as being "effective" or "ineffective" within the context of a general aim. Thus, the general objective of the activity to be studied must be stated. For instance, the general aim of salespeople is specifically to sell goods to customers (Swan \& Rao, 1975). According to Flanagan (1954), the CIT can record specific behaviors from those in the best position to make the necessary observations and evaluations which can be accomplished by the individuals performing the activity. In particular, the objective is to gain an understanding of "critical behaviors" from the perspective of the individual (Chell, 2004).

Flanagan advocated four ways of obtaining recalled data: "1) individual interviews; 2) group interviews; 3) questionnaires; and 4) record forms" (Butterfield et al., 2005, p. 478). Obtaining recalled data can consist of eliciting a story from respondents about something that happened to them. In this sense it represents a description (Pellat et al., 2010). Gremler (2004) states that "once the stories (critical incidents) have been collected, content analysis of the stories takes place" (p. 66). Gremier (2004) adds that information contained in the stories is then "scrutinized" to identify data categories that summarize and describe the incidents. The categories of classification can be determined using an inductive approach, ex post facto. From a positivist perspective, the goal of the content analysis is the development of a classification system to provide insights regarding the frequency and patterns of factors affecting the studied phenomenon (Gremler, 2004).

In the methodology sections of this chapter, we present a detailed exemplar of the CIT, combined with content analysis: (1) data collection by means of an open-ended questionnaire; (2) inductive identification of categories; and (3) coding of empirical material concerning critical emotional behaviors related to success and failure in sales interactions.

\subsection{Combining the CIT with Content Analysis and Generating Meaning with Numbers}

After considering several other research methods, we selected the critical incident technique as the most appropriate for identifying the emotional behaviors involving or hindering selling success during salesperson-customer interactions. As mentioned above, the CIT can 
actually provide a clear understanding of what behaviors are effective or ineffective (Swan \& Rao, 1975, p. 298). In addition, the CIT method is especially useful when the topic being researched has been sparsely documented, or when a thorough understanding is needed to describe or explain a phenomenon (Gremler, 2004, p. 67). It is an exploratory method for increasing knowledge about little-known phenomena.

As mentioned earlier, previous research on how salespeople's emotion management impacts selling success is both sparse and conflicting. In addition, the CIT has been primarily dedicated to the recording of behaviors that lead to success or failure in accomplishing a specific task (Ronan \& Latham, 1974). A recognized effective investigative tool (Butterfield et al., 2005), the CIT makes it possible to further examine emotional behaviors contributing to successful and failed sales interactions.

Flanagan (1954) considered the CIT not as a rigid set of rules governing data collection and analysis, but rather as a "procedure" for identifying important facts concerning phenomena in specific situations (p. 335). Indeed, the CIT consists of a flexible set of principles which must be modified and adapted (Butterfield et al., 2005). Due to its exploratory-investigative nature, and also because of its flexibility as a qualitative research method (Butterfield et al., 2005), the CIT has tremendous advantages. One of them is that, when used with content analysis, the CIT utilizes both qualitative and quantitative examination of empirical material. Indeed, when qualitative researchers take raw data and place them into categories in which they attach codes or designate as themes, "they are drawing from the numbered natured of phenomena for their analysis" (Sandelowski, 2001, p. 231).

Qualitative and quantitative examinations of empirical material are usually thought to be antithetical forms of analysis (Bitner et al., 1990; Sandelowski, 2001), but their combination actually provides both "rigor and vigor" (Bitner et al., 1990, p. 73). When analyzing qualitative data, to display information numerically make it possible to have patterns emerge with more clarity (Dey, 1993). Indeed, "numbers intended primarily to document and verify will also inevitably enable researchers to extract more meaning from qualitative data" (Sandelowski, 2001, p. 231). Though numbers are used to generate meaning, they also help to document the steps taken to arrive at meaning. 


\subsection{Epistemological Perspective}

When Flanagan wrote his classic article in 1954, "a positivist approach to social science investigations was largely unquestioned. It was the dominant paradigm in the social sciences as it was in the natural sciences" (Chell, 2004, p. 45). Though a qualitative research tool, the CIT was primarily viewed as a scientific procedure to objectivate and to measure existing phenomena in order to predict and control them in the field of job and task analysis. However, postulates on which the CIT is based are related to a quantitative research perspective. Therefore, a quantitative terminology as well as quantitative validity and reliability checks are used by some researchers (Butterfield et al. 2005). This research method may be applied not only in a positivist tradition, but also in an interpretivist one (Gremler, 2004), or even in a phenomenological or post-modern perspective (Chell, 2004). The research design combining the CIT with content analysis assumes a predominantly positivist approach. Indeed, "qualitative work can be positivist: it can attempt to document practices [or behaviors] that lead consistently to one set of outcomes rather than another" (Lin, 1998, p. 162). Thus, like prior CIT studies (Swan \& Rao, 1975) our perspective is more explanatory than comprehensive.

\section{Methodology}

This section is dedicated to describing the data collection, category development, and coding processes of the empirical material. Moreover, the unit of analysis is specified. We also indicate how the reliability of the coding process was measured.

\subsection{Data Collection}

This exploratory and inductive qualitative study involved more than 400 hundred salesperson-customer interactions. We collected descriptions of salespeople's and customers' emotional behaviors during both successful and failed sales interactions, involving a subsequent buying decision or decision not to buy (Tang et al., 2013a; Tang et al., 2013b). For our CIT survey, we devised a self-administered open-ended questionnaire (Smith et al., 1991) in two versions. Version A concerned successful sales interactions. Version B was related to failed sales interactions. We asked salespeople to think about a recent sales interaction that was either successful (version A) or not (version B). The purpose was to have them describe their emotional states and emotional behaviors, specifically related to their control over their emotions during the sales interaction regardless 
of its success. We asked respondents to report whether they managed their emotions or whether they expressed genuine ones. We also asked respondents to narrate the customers' emotional behaviors, attitudes, and behaviors (e.g. to ask a question). We tested the questionnaire five times with groups composed respectively of $6,13,12,27$ and 6 marketing and sales employees. After each test, we reformulated some questions to ensure that they were understood and interpreted as intended (Foddy, 1993). Table 1 presents the structure of the questionnaire.

Table 1. Structure of the Open-ended Questionnaire.

The open-ended questionnaire is composed of:

An introduction:

"Do you remember a recent 'successful' [version A] or "unsuccessful" [version B] sales interaction with a customer, either face-to-face or over the phone? Answer the questions on the following pages in the MOST DETAILED WAY POSSIBLE".

Three series of open-ended questions about:

- the context of the sales interaction

- the salesperson's control over his or her emotions

- the customers' emotional behaviors

A demographics section asking about:

- Status (e.g. salaried salesperson or commercial agent), activity sector, education,...

In the course of two rounds spread out over 18 months, we sent questionnaires by email to a total of 226 employees in marketing or sales departments in various business sectors. The first campaign involved 95 employees and the second involved 131. These employees had to send the questionnaire (version $A$ and $B$ ) respectively to two salespeople in their professional networks. We collected a total of 483 questionnaires. Respondents typed more than $95 \%$ of the completed questionnaires and handwrote the remainder. We could not use 29 questionnaires either because they were incomplete, their narrative lacked substance, or for other reasons having to do with the research requirements (e.g. description of a purchasing event rather than a sales event; illegible handwriting, etc.). Thus, we could utilize 454 responses for the objectives of the study. About half of the usable questionnaires concerned successful sales interactions and the other half concerned failed ones. 


\subsection{Specification of the Unit of Analysis}

Keaveney (1995) indicates that "because the term 'critical incident' can refer to either the overall story or to discrete behaviors contained within the story, the first step in data analysis is to determine the appropriate unit of analysis" (p. 73). Therefore, we differentiated between "critical incidents" (i.e. descriptions of the sales interactions made by the respondents in the questionnaires) and "discrete behaviors" (i.e. specific emotional behaviors reported in these overall descriptions). As mentioned in Appendices 1 and 2, we designated these discrete behaviors as "critical emotional episodes" or "emotional episodes."

To further qualify these emotional episodes, we determined that units of meaning (Dumez, 2016) would best preserve the specificity of the data. Units to be coded corresponded to salespeople's and customers' emotional behaviors, e.g. "I really had to manage my emotions with this client" or "the client was angry" (see Appendices 1 and 2 for other examples). We identified a total of 2351 units in the usable questionnaires: 1288 in the descriptions concerning successful sales interactions and 1063 in those with regard to failed ones.

\subsection{Category Development}

To get acquainted with and to prepare the empirical data, the first author read the answers provided in the 194 open-ended questionnaires collected in the first round of data collection. He rejected a total of 10 questionnaires. We assigned the 184 usable questionnaires a number for data management purpose. Reading and rereading of the answers provided in the open-ended questionnaires (Bitner et al., 1990) made it possible to identify categories (Keaveney, 1995) of "critical emotional episodes." We sorted these categories into groups and subgroups (Bitner et al., 1990). We then designed a thematic tree ordering the 36 identified categories (e.g. "salesperson incapacity to hide emotions") into 14 subgroups (e.g. "salesperson emotion dissimulation"), ordered into four generic groups (e.g. "salesperson self-focused emotional labor") (Paillé \& Mucchielli, 2016, p. 317). After rereading of the answers given in the open-ended questionnaires, we adjusted some categories in the thematic tree. Categories were then named (Gremler, 2004).

The first author developed a categorization coding matrix including a definition for each category. We then randomly selected some questionnaires. We identified "critical emotional episodes" by highlighting units of meaning while reading the answers. 
We created a sample of about 150 "critical emotional episodes." The first author then classified these units of meaning to be coded under the appropriate category (Dumez, 2016). This was followed by reverse coding of the sample in conjunction with correction of coding errors (Van Der Maren, 2009).

Table 2. Categories and Subgroups Concerning Salespeople's Emotional Behaviors (Group 1).

\begin{tabular}{|c|c|c|}
\hline Group 1 & Subgroups & Categories \\
\hline \multirow[t]{11}{*}{$\begin{array}{l}\text { Salesperson(s)' } \\
\text { emotional behavior }\end{array}$} & $\begin{array}{l}\text { 1.1 Emotional behavior focused } \\
\text { on client(s) }\end{array}$ & $\begin{array}{l}\text { 1.1.1 Expression of genuine emotions } \\
\text { (i.e. emotional authenticity) }\end{array}$ \\
\hline & & $\begin{array}{l}\text { 1.1.2 Control of felt and expressed } \\
\text { emotions }\end{array}$ \\
\hline & & 1.1.3 Hiding of felt emotions \\
\hline & & 1.1.4 Empathy toward client(s) \\
\hline & $\begin{array}{l}1.2 \text { Difficulty or inability to } \\
\text { manage emotions }\end{array}$ & $\begin{array}{l}\text { 1.2.1 Difficulty or incapacity to control } \\
\text { felt and/or expressed emotions or the } \\
\text { client(s)' ones }\end{array}$ \\
\hline & & $\begin{array}{l}\text { 1.2.2 Difficulty or incapacity to hide own } \\
\text { emotions }\end{array}$ \\
\hline & & $\begin{array}{l}\text { 1.2.3 Very negative felt and expressed } \\
\text { emotional reaction }\end{array}$ \\
\hline & & $\begin{array}{l}\text { 1.2.4 Emotional "discomfort" before } \\
\text { sales interaction }\end{array}$ \\
\hline & 1.3 Emotional valence during & 1.3.1 Positive valence \\
\hline & sales interaction & 1.3.2 Negative valence \\
\hline & & $\begin{array}{l}\text { 1.3.3 Indifference or absence of } \\
\text { emotions }\end{array}$ \\
\hline
\end{tabular}

The same researcher coded the same sample one month later, again with correction of coding errors. Another author then coded that sample. Both researchers then discussed of discrepancies (Dumez, 2016) which led to the revision of categories which included a compression of their number and redefinition of some of them. The thematic tree and the coding matrix resulted in 22 categories (vs. 36 earlier), classified into six subgroups, themselves organized into two groups (see Table 2 and Table 3). As reported in Table 2 above, 11 categories concern the salespeople's emotional behaviors (Group 1), e.g. 
"expression of genuine emotions." We regrouped these categories to form thematic subgroups, e. g. "emotional behavior focused on client(s)."

We present representative quotes for each coding category in Appendices 1 and 2. Table 3 below presents the 11 categories and subgroups concerning the customer(s)' emotional behaviors (Group 2).

\subsection{Coding of the First Data Collection and Reliability Check}

By highlighting the "units of meaning" (see Appendices 1 and 2 for examples), the first author identified the "critical emotional episodes" in the remaining body of empirical data from the first round of data collection. We processed the coding of this written material, using the coding matrix, in an uninominal way; that is, each unit to be coded could only be classified in one category (Weber, 1990). The researchers' reverse coding with correction of coding errors led to refining the definitions of the categories.

Table 3. Categories and Subgroups Concerning Customers' Emotional Behaviors (Group 2).

\begin{tabular}{|c|c|c|c|}
\hline Group 2 & & Subgroups & Categories \\
\hline \multirow{13}{*}{$\begin{array}{l}\text { Client(s)' } \\
\text { behavior }\end{array}$} & \multirow[t]{13}{*}{ emotional } & \multirow{5}{*}{$\begin{array}{l}2.1 \text { Self-focused emotional } \\
\text { behavior }\end{array}$} & 2.1.1 Expression of genuine \\
\hline & & & emotions (i.e. emotional authenticity) \\
\hline & & & 2.1.2 Management of own emotions \\
\hline & & & $\begin{array}{l}\text { 2.1.3 Difficulty or incapacity to } \\
\text { manage own emotions }\end{array}$ \\
\hline & & & $\begin{array}{l}\text { 2.1.4 Strong expression of } \\
\text { annoyance and anger }\end{array}$ \\
\hline & & \multirow[t]{4}{*}{$\begin{array}{l}2.2 \text { Emotional behavior focused } \\
\text { on salesperson(s) }\end{array}$} & $\begin{array}{l}2.2 .1 \quad \text { Empathy } \\
\text { salesperson(s) }\end{array}$ \\
\hline & & & $\begin{array}{l}\text { 2.2.2 Perception of salesperson(s)' } \\
\text { negative emotions }\end{array}$ \\
\hline & & & 2.2.3 Management \\
\hline & & & salesperson(s)' emotions \\
\hline & & \multirow{4}{*}{$\begin{array}{l}\text { 2.3 Emotional valence expressed } \\
\text { during sales interaction }\end{array}$} & 2.3.1 Positive valence \\
\hline & & & 2.3.2 Negative valence \\
\hline & & & $\begin{array}{l}\text { 2.3.3 Neutral valence or negative } \\
\text { valence followed by positive }\end{array}$ \\
\hline & & & $\begin{array}{l}\text { 2.3.4 Indifference or absence of } \\
\text { expressed emotions }\end{array}$ \\
\hline
\end{tabular}


Subsequently, as presented in Table 4 below, we evaluated intra-coder reliability. In a random selection of questionnaires, we identified the "critical emotional episodes," highlighting the units of meaning in order to discover at least 150 units to be coded. The total sample size consisted of 158 units. To measure inter-coder reliability in a data sample, the sample must contain more than 150 units (Guetzkow, 1950). The same rule can be applied to intra-coder reliability. We completed an uninominal classification of the units to be coded, using the coding matrix. Then, we performed reverse coding of the sample with a correction of coding errors.

\subsection{Coding of the Second Data Collection and Reliability Check}

Again, the same researcher coded the same sample one month later. We then calculated the Cohen's (1960) Kappa. The Kappa equals .917, which is an excellent result (Landis \& Koch, 1997). We also performed a calculation of the Perreault and Leigh's (1989) Ir. The Ir equals .959, the reliability is thus very good (Gremler, 2004; Perreault \& Leigh, 1989). Based on the results of both the coding and the counter-coding, we made an adjustment of the coding of the sample. To measure inter-coder reliability (see Table 4), a second researcher coded the sample. The Kappa equals .728, which is a good result (Landis \& Koch, 1997). The Perreault and Leigh's (1989) Ir equals .861, which is also evidence of good reliability (Gremler, 2004).

Table 4. Values of Reliability Indexes during the First Round of Data Collection and Coding

\begin{tabular}{lll}
\hline & Intra-coder reliability & Inter-coder reliability \\
\hline Values of Cohen's & 0.917 & 0.728 \\
Kappa & & \\
\hline Values of Perreault and & 0.959 & 0.861 \\
Leigh's Ir & & \\
\hline
\end{tabular}

The first author read the answers provided in the 289 open-ended questionnaires collected in the second round of data collection. We rejected 19 questionnaires. We then assigned a number to the 270 usable open-ended questionnaires. Like for the first data collection, we followed this by identification of the "critical emotional episodes" (highlighting the units of meaning) in the questionnaires and "uninominal" classification into the categories. We then re-read all the responses and corrected coding errors. 
We measured intra-coder reliability the same way as for the first data collection with a sample size of 155 units. Kappa equals .893, a very good result according to Landis and Koch (1997). The Ir equals .947, which is evidence of excellent reliability (Perreault \& Leigh, 1989). We then adjusted the coding of the sample based on the results of both coding and counter-coding. Evaluation of intercoder reliability was also satisfactory, with a good result (.750) for Cohen's Kappa (Landis \& Koch, 1997), and a good reliability score (.873) for the Ir index (Gremler, 2004). Table 5 below presents the values of reliability indexes during the second round.

Table 5.Values of Reliability Indexes during the Second Round of Data Collection and Coding

\begin{tabular}{lll}
\hline & Intra-coder reliability & Inter-coder reliability \\
\hline Values of Cohen's & 0.893 & 0.750 \\
Kappa & & \\
\hline $\begin{array}{l}\text { Values of Perreault and } \\
\text { Leigh's Ir }\end{array}$ & 0.947 & 0.873 \\
\hline
\end{tabular}

\section{FINDINGS}

For each of the 22 categories, we calculated relative and absolute frequencies based on the number and percentage of respondents mentioning the category at least once. We made this calculation using Sphinx Plus and Sphinx IQ2 softwares, which we configured for this process. We identified quotes in the completed questionnaires to provide a more comprehensive understanding of the emotional behaviors. See Appendices 1 and 2 for examples. For some salespeople, emotion management was a form of theatricality. Referring to a sales interaction, a respondent claimed that "it was nothing but theatrical, with a great [felt] culpability. During these kind of sales [interactions] I don't show my real emotions but rather faked ones, overplayed."

More than 50 completed questionnaires reported salespeople's emotion management after a customer's decision whether to purchase or not the product or service. For instance, a respondent reported, "I was disappointed in my inner-self, but I didn't show it." Emotion management was performed even after a purchase decision, while the salesperson went on interacting with the client, either face-to-face or on the phone. Even when the decision was positive (i.e. a purchase), some salespeople claimed they still had to manage their emotions. For example, one respondent said “[...] once the sale is over and successful, I don't show my 
satisfaction to the client, I must stay 'neutral' and I don't display my real emotions at that very moment."

Salespersons also expressed genuine emotions during sales interactions. Results showed that salespeople's emotional authenticity was associated with successful sales (32\%). According to some respondents, emotional authenticity was indeed part of effective selling. One salesperson declared that the emotions expressed during the sales interaction "were sincere" and added, "I believe that one should strive to be as natural as possible."

In comparison with emotional authenticity, salespeople's control and dissimulation of emotions were more often associated with successful sales (73\%). But control and dissimulation were also linked to sales failure (78\%). During sales interactions, salespeople had a greater tendency to manage their emotions, rather than being emotionally authentic. For many salespeople, emotion management was part of the work role. As the following comment by a salesperson illustrated, "I must always be smiling and respectful. The company's image is at stake." Furthermore, some respondents reported that it was "professional" to perform emotion management (i.e. emotional labor). For example, one salesperson said, "Emotion management was of utmost importance at that very moment, because I had to stay professional." Another salesperson indicated, "I managed my emotions the best I could in order to look professional."

It should be emphasized that emotion management is not only performed face-to-face but also during phone interactions, as related by this salesperson:

"Emotion management is very important, especially for me because I contact my clients only by phone. A smile can be heard, even when not in face-to-face. Especially when handling [customers'] objections. You can't lose control when the client says, 'it's too expensive,' or 'I don't need it'."

Results revealed a $28 \%$ relationship between sales failures and customers' expressions of annoyance or anger. One respondent said, "besides the 'rejection' the client felt for the service [I was proposing], he let himself be driven by his emotions of anger and discontent." Findings also demonstrated a $20 \%$ relationship between sales failures, the salespeople's difficulties or inabilities to hide emotions, and the inability to manage their own or their clients' emotions. 
Salespeople's negative emotions (i.e. a negative emotional valence) are associated with failed sales interactions (24\%). One respondent noted, "During this kind of sales conversation, the only felt emotion was a feeling of mistrust." Moreover, $26 \%$ of the respondents reported having positives emotions during a successful sale. "I was serene," wrote a saleswoman while describing a successful sales interaction. Sales people associated a positive emotional valence displayed by the customer with a successful sale and a negative valence (e.g. a "skeptical" client) was associated with a failed one.

\section{FINAL CONSIDERATIONS}

Results corroborate previous findings concerning frontline employees, but not specifically salespeople. Our study notably contributes to the literature by extending some results (Grandey \& Gabriel, 2015) to sales management. Results also lead to new conclusions. The fact that some salespeople consider emotion management as a form of theatricality seems to corroborate Hochschild's (1983) work that linked emotional labor to dramaturgy. Furthermore, some descriptions of salesperson-customer interactions indicated that emotion management was also performed after the customer's decision whether to purchase or not the product or service. To the best of our knowledge, no empirical study had revealed this particular phenomenon. In some cases, emotional labor seemed to be even more intense after the customer's decision, especially if she/he decided not to buy the product/service.

Some salespeople reported expressing genuine emotions during interactions with customers. This supports previous findings such as the display of naturally felt emotions (conforming with emotional rules) as one dimension of emotional labor (Ashforth \& Humphrey, 1993). Additionally, it supports these as being an individual "strategy" (Diefendorff et al., p. 340). Some researchers claimed that authenticity has a positive impact on customers' attitudes (e.g. favorable impressions in customers' minds) and behaviors (e.g. reactions such as purchasing the product or service) (Ashkanasy \& Daus, 2002; Grandey et al., 2005). For many respondents, emotion management was part of the work role and of professionalism. This corroborates the body of literature which links emotional labor to job requirements and to professional norms (e.g. Bhave \& Glomb, 2016). One of the employees' motives for emotion regulation at work was indeed to conform to these norms (Adelmann, 1995).

The stakes are high concerning practical implications for these findings. Previous findings showed that "faking emotions" had a negative impact on employees' well-being, namely 
burnout (Grandey \& Gabriel, 2015). In addition, "faking emotions" can actually be perceived by customers (Hülsheger \& Schewe, 2011) and "exerts negative effects when customers perceive it as such" (Groth et al., 2009, p. 969). We know that customers prefer to be treated in an honest and authentic way (Hennig-Thurau et al., 2006). This is one of the reasons why authenticity triggers positive emotions "within customers" (Hennig-Thurau et al., 2006, p. 61).

The CIT has some methodological drawbacks. A low response rate is likely because the CIT requires individuals to take time and effort to describe situations in detail (Johnston, 1995). In addition, respondents may not be accustomed, or willing, to take the time to make descriptions of critical incidents (Edvardsson \& Roos, 2001). Furthermore, the "incident" can later be reinterpreted by respondents (Johnston, 1995). Being a retrospective method, the CIT can produce recall bias (Pellat et al., 2010) or be affected by memory lapses (Singh \& Wilkes, 1996). To some extent, the critical incident technique has also been criticized for its drawbacks concerning both reliability and validity (Chell, 2004).

Furthermore, the CIT shares the disadvantages of content analysis when the descriptions of the critical incidents are analyzed using a content analysis procedure (Bitner et al., 1990). One of the main disadvantages stems from the ambiguity associated with category labels and coding rules (Weber, 1990). However, despite its methodological drawbacks, the critical incidents technique offers tremendous methodological benefits (Bitner et al., 1994; Flanagan, 1954).

Acknowledgments The authors would like to thank following scholars for their diverse contributions: Pierre Paillé, Sherbrooke University, Canada; Hervé Dumez, Ecole Polytechnique, France; David Vidal, University of Montpellier, France; Francine Klein, University of Wisconsin, U.S.A.; Eric Kraemer, University of Wisconsin, U.S.A.

\section{REFERENCES}

Ashforth, B. E., \& Humphrey, R. H. (1993). Emotional labor in service roles: The influence of identity. Academy of Management Review, 18(1), 88-115. https://doi.org/10.2307/258824

Adelmann, P. K. (1995). Emotional labor as a potential source of job stress. In S. L. Sauter \& L. R. Murphy (Eds.), Organizational risk factors for job stress (pp. 371-381). American Psychological Association. https://doi.org/10.1037/10173-023

Ashkanasy, N. M., \& Daus, C. S. (2002). Emotion in the workplace: The new challenge for managers. Academy of Management Perspectives, 16(1), 76-86. https://doi.org/10.5465/ame.2002.6640191

Bagozzi, R. P., Gopinath, M., \& Nyer, P. U. (1999). The role of emotions in marketing. Journal of the Academy of Marketing Science, 27(2), 184-206. https://doi.org/10.1177/0092070399272005

Bhave, D. P., \& Glomb, T. M. (2016). The role of occupational emotional labor requirements on the surface acting-job satisfaction relationship. Journal of Management, 42(3), 722-741. https://doi:10.1177/0149206313498900 
Bitner, M. J., Booms, B. H., \& Tetreault, M. S. (1990). The service encounter: Diagnosing favorable and unfavorable incidents. Journal of Marketing, 54(1), 71-84. https://doi.org/10.2307/1252174

Bitner, M. J., Booms, B. H., \& Mohr, L. A. (1994). Critical service encounters: The employee's viewpoint. Journal of Marketing, 58(4), 95-106. https://doi.org/10.2307/1251919

Brotheridge, C. M. (2006). A review of emotional labour and its nomological network: practical and research implications. Ergonomia, 4(28), 295-309.

Butterfield, L. D., Borgen, W. A., Amundson, N. E., \& Maglio, A. S. T. (2005). Fifty years of the critical incident technique: 1954-2004 and beyond. Qualitative Research, 5(4), 475-497. https://doi.org/10.1177/1468794105056924

Chell, E. (2004). Critical incident technique. In C. Cassell \& G. Symon (Eds.), Essential guide to qualitative methods in organizational research (pp. 45-60). SAGE. http://dx.doi.org/10.4135/9781446280119.n5

Cohen, J. (1960). A coefficient of agreement for nominal scales. Educational and Psychological Measurement, 20(1), 37-46. https://doi.org/10.1177/001316446002000104

Dey, I. (1993). Qualitative data analysis: A userfriendly guide for social scientists. Routledge. https://doi.org/10.1017/S135246580001554X

Diefendorff, J. M., \& Gosserand, R. H. (2003). Understanding the emotional labor process: A control theory perspective. Journal of Organizational Behavior: The International Journal of Industrial, Occupational and Organizational Psychology and Behavior, 24(8), 945-959. https://doi.org/10.4324/9780203412497

Diefendorff, J. M., Croyle, M. H., \& Gosserand, R. H. (2005). The dimensionality and antecedents of emotional labor strategies. Journal of Vocational Behavior, 66(2), 339-357. http://dx.doi.org/10.1016/j.jvb.2004.02.001

Dumez, H. (2016). Comprehensive research: A methodological and epistemological introduction to qualitative research. Copenhagen Business School Press.

Edvardsson, B., \& Roos, I. (2001). Critical incident techniques: Towards a framework for analysing the criticality of critical incidents. International Journal of Service Industry Management, 12(3), 251-268. http://dx.doi.org/10.1108/EUM0000000005520

Ekman, P., Friesen, W. V., \& Ancoli, S. (1980). Facial signs of emotional experience. Journal of Personality and Social Psychology, 39(6), 1125-1134. https://doi.org/10.1037/h0077722

Flanagan, J. C. (1954). The critical incident technique. Psychological Bulletin, 51(4), $327-358$. https://doi.org/10.1037/h0061470

Foddy, W. (1993). Constructing questions for interviews and questionnaires: Theory and practice in social research. Cambridge University Press. https://doi.org/10.1017/CBO9780511518201

Grandey, A. A., \& Gabriel, A. (2015). Emotional Labor at a Crossroads: Where Do We Go from Here?. Annual Review of Organizational Psychology and Organizational Behavior, 2(1), 323-349. https://doi.org/10.1146/annurev-orgpsych-032414-111400

Grandey, A. A., Fisk, G. M., Mattila, A. S., Jansen, K. J., \& Sideman, L. A. (2005). Is "service with a smile" enough? Authenticity of positive displays during service encounters. Organizational Behavior and Human Decision Processes, 96(1), 38-55. https://doi.org/10.1016/j.obhdp.2004.08.002

Gremler, D. D. (2004). The critical incident technique in service research. Journal of Service Research, 7(1), 65-89. https://doi.org/10.1177/1094670504266138

Groth, M., Hennig-Thurau, T., \& Walsh, G. (2009). Customer reactions to emotional labor: The roles of employee acting strategies and customer detection accuracy. Academy of Management Journal, 52(5), 958-974. https://doi.org/10.5465/amj.2009.44634116

Guetzkow, H. (1950). Unitizing and categorizing problems in coding qualitative data. Journal of Clinical Psychology, 6(1), 47-58. https://doi.org/10.1002/1097-4679(195001)6:1<47::AIDJCLP2270060111>3.0.CO;2-I

Hennig-Thurau, T., Groth, M., Paul, M., \& Gremler, D. D. (2006). Are all smiles created equal? How emotional contagion and emotional labor affect service relationships. Journal of Marketing, 70(3), 58-73. https://doi.org/10.1509/jmkg.70.3.058

Hochschild, A. R. (1983). The managed heart. University of California Press. https://doi.org/10.1002/pam.4050030365 
Hülsheger, U. R., \& Schewe, A. F. (2011). On the costs and benefits of emotional labor: A meta-analysis of three decades of research. Journal of Occupational Health Psychology, 16(3), 361-389. https://doi.org/10.1037/a0022876

Johnston, R. (1995). The determinants of service quality: Satisfiers and dissatisfiers. International Journal of Service Industry Management, 6(5), 53-71. https://doi.org/10.1108/09564239510101536

Keaveney, S. M. (1995). Customer switching behavior in service industries: An exploratory study. Journal of Marketing, 59(2), 71-82. https://doi.org/10.2307/1252074

Landis, J. R., \& Koch, G. G. (1977). An application of hierarchical kappa-type statistics in the assessment of majority agreement among multiple observers. Biometrics, 33(2), 363-374. https://doi.org/10.2307/2529786

Lin, A. C. (1998). Bridging positivist and interpretivist approaches to qualitative methods. Policy Studies Journal, 26(1), 162-180. https://doi.org/10.1111/j.1541-0072.1998.tb01931.x

Paillé, P., \& Mucchielli, A. (2016). L'analyse qualitative en sciences humaines et sociales [Qualitative analysis in human and social sciences] (4th ed.). Armand Colin.

Pellat, G., Poujol, F., \& Siadou-Martin, B. (2010). L'orientation client du vendeur du point de vue du consommateur: les apports de la théorie de l'attachement [The customer's evaluation of the salesperson's customer orientation: the attachement theory perspective]. Management \& Avenir, (1), 246-266.

Perreault Jr, W. D., \& Leigh, L. E. (1989). Reliability of nominal data based on qualitative judgments. Journal of Marketing Research, 26(2), 135-148. https://doi.org/10.2307/3172601

Pugliesi, K. (1999). The consequences of emotional labor: Effects on work stress, job satisfaction, and wellbeing. Motivation and Emotion, 23(2), 125-154. https://doi.org/10.1023/A:1021329112679

Rafaeli, A., \& Sutton, R. I. (1987). Expression of emotion as part of the work role. Academy of Management Review, 12(1), 23-37. https://doi.org/10.2307/257991

Ronan, W. W., \& Latham, G. P. (1974). The reliability and validity of the critical incident technique: A closer look. Studies in Personnel Psychology, 6(1), 53-64.

Sandelowski, M. (2001). Real qualitative researchers do not count: The use of numbers in qualitative research. Research in nursing \& health, 24(3), 230-240. https://doi.org/10.1002/nur.1025

Scherer, K. R. (2005). What are emotions? And how can they be measured? Social Science Information, 44(4), 695-729. https://doi.org/10.1177/0539018405058216

Singh, J., \& Wilkes, R. E. (1996). When consumers complain: A path analysis of the key antecedents of consumer complaint response estimates. Journal of the Academy of Marketing Science, 24(4), 350-365. https://doi.org/10.1177/0092070396244006

Smith, M. E., Lowe, A., \& Thorpe, R. (1991). Management research: An introduction. SAGE.

Sutton, R. I., \& Rafaeli, A. (1988). Untangling the relationship between displayed emotions and organizational sales: The case of convenience stores. Academy of Management Journal, 31(3), 461-487. https://doi.org/10.2307/256456

Swan, J. E., \& Rao, C. P. (1975). The critical incident technique: A flexible method for the identification of salient product attributes. Journal of the Academy of Marketing Science, 3(2), 296-308. https://doi.org/10.1177/009207037500300220

Tang, C., Seal, C. R., \& Naumann, S. E. (2013a). Emotional labor strategies, customer cooperation and buying decisions. Journal of Management and Marketing Research, 13(1), 1-15.

Tang, C., Seal, C. R., Naumann, S. E., \& Miguel, K. (2013b). Emotional labor: The role of employee acting strategies on customer emotional experience and subsequent buying decisions. International Review of Management and Marketing, 3(2), 50-57.

Thoits, P. A. (1996). Managing the emotions of others. Symbolic Interaction, 19(2), 85-109. https://doi.org/10.1525/si.1996.19.2.85

Van Der Maren, J. M. (2009). Codage inversé [Reverse coding]. In A. Mucchielli (Ed.), Dictionnaire des méthodes qualitatives en sciences humaines [Dictionary of qualitative methods in the humanities] ( $p$. 19). Armand Colin. 
Wharton, A. S., \& Erickson, R. I. (1993). Managing emotions on the job and at home: Understanding the consequences of multiple emotional roles. Academy of management Review, 18(3), 457-486. https://doi.org/10.5465/amr.1993.9309035147

Weber, R. P. (1990). Basic content analysis. SAGE. https://dx.doi.org/10.4135/9781412983488

\section{Appendix 1}

Coding Category Representative Quotes (Group 1)1

\section{Coding categories \\ .1 Expression of genuine emotions (i.e. \\ emotional authenticity) \\ 1.1.2 Control of felt and
expressed emotions}

3 Hiding of felt emotions

\subsubsection{Empathy toward} client(s)

?.1 Difficulty or incapacity to control felt and/or expressed emotions or the client(s)' ones

?.2 Difficulty or incapacity to hide own emotions

?.3 Very negative felt and expressed emotional reaction

.4 Emotional "discomfort" before sales interaction

1.3.1 Positive valence

1.3.2 Negative valence

3 Indifference or absence of emotions

\section{ategories concerning salespeople's emotional behaviors}

Representative quotes (emotional behavior in bold)

I stayed very natural and honest with the customers. My first goal was to meet their expectations and needs. I wanted them first to sign and second to feel that if they have a problem they would contact us again. When you are in sales, you need to put your feelings aside and learn to listen to the customer. And you need to know that as long as there is no signed contract, they are only prospects [and no actual clients]. I hid all my feelings and remained smiling and friendly while hiding the stress of not showing my emotions: working on my breathing, using a warm welcoming tone of voice, nodding in agreement. I simply adopted the posture I learned about during an internal training workshop in my company on communication and body language. Thus, I let nothing show to the

customer.

I am working more on empathy and try to understand the customer's real interests and criteria for purchasing.

After validating the customer's intention to buy, and following the latter's expression of annoyance, I did not sufficiently control my feelings and showed my real emotions (showing anger at the customer who did not keep his calm, who made derogatory remarks on the brand and our sales competencies) namely by raising my voice.

It was very hard for me to hide my emotions because of the complicity that developed between us. However I managed to remain professional and not slip into a friendly relationship.

However when I realized in the course of our verbal interaction that the customer was indirectly expressing his dissatisfaction about the pricing of these sneakers, I suddenly froze and the customer must have felt it immediately. The objection made by the client and my change in behavior was probably fatal for the sale.

The situation couldn't unfold as I had wished because at that moment the number of customers in the store hindered a sales' type discussion and argumentation: This increased number of customers created pressure because I had to answer several customers' questions simultaneously.

I was very much at ease, smiling and interested in getting to know better both the [client's] organization and the person I was talking to. I was annoyed because the customer didn't let me talk and was constantly interrupting me. My stress increases as well as my annoyance because my professional conscience pushes me to stay calm and channel the client's exasperation. $\mathrm{n}$ a commercial negotiation we talk about money. Money has nothing to do with affect. Hence there is no space for feelings. [...] in fact I had no feelings whatsoever.

\footnotetext{
${ }^{1}$ Grammatical errors in the original French responses have been corrected in the translation for ease of comprehension.
} 
Appendix 2

Coding Category Representative Quotes (Group 2)2

Categories concerning customers' emotional behaviors

Coding categories

Representative quotes (emotional behavior in bold)

2.1.1 Expression of genuine emotions (i.e. emotional authenticity)

2.1.2 Management of own emotions [The customer] was in a listening mode. He shared his feelings about the products I was showing him. He told me clearly what he liked or disliked.

The purchasing manager remained cold, he was also hiding his emotions. Buyers of these kinds of brands are often cold stone during sales transactions.

1.3 Difficulty or incapacity to manage own emotions

2.1.4 Strong expression of annoyance and anger

2.2.1 Empathy toward salesperson(s)

2.2.2 Perception of salesperson(s)' negative emotions

2.2.3 Management of salesperson(s)' emotions

2.3.1 Positive valence

2.3.2 Negative valence

2.3.3 Neutral valence or negative valence followed

by positive

Indifference or absence of expressed emotions
Our second encounter took place over the phone and we were extremely busy, therefore feelings had to be put aside so we could go on. When I finally had the exchange with my professional customer, I felt some kind of

embarrassment and empathy.

While cashing his money, this man shows his dissatisfaction by complaining on his way out and ignoring basic rules of politeness. If I had insisted a little longer, I think this person would have raised his voice to express his impatience to leave, to not have to speak with a sales person, and his wish to just cash his money. Such behavior is common in my field of work. Beyond his resentment regarding the service, this customer let himself be carried away by his feelings of anger and dissatisfaction. The customer's anger flared up immediately, assuming that the store somehow owed it to him to buy a desk.

Then customer noticed my lack of control and immediately turned against me, which in retrospect is understandable: I should have kept my calm and showed the customer that I was open to discussion and negotiation. I did not handle my emotions well, probably because of a natural reflex to not "be taken advantage of" by saying too much.

This customer was specifically looking for the best price by trying to destabilize me and break me by already knowing all the competitors' prices and quoting them to me.

Her behavior was very cheerful. One could feel her enthusiasm and her openness to discussion. This made the sale easier and resulted in an additional sale.

This was a very stressed and anxious person, so I had to argue with him to reassure him regarding my expertise.

During this sale, the customer went from negative emotions (agressivity, anger, frustration, unfairness) to a state of well-being. How? Simply by being listened to. For we live in a world where everything has to go fast, but in our profession, it is impossible to do without that because it constitutes the basis for a successful sale.

The customer remained very cold and closed up; he did not let any emotion or sensitivity show during our meeting.

2 Grammatical errors in the original French responses have been corrected in the translation for ease of comprehension. 